\title{
ADVERSE CHILDHOOD EXPERIENCES IN ALBERTA, CANADA: A POPULATION BASED STUDY
}

\author{
Sheila McDonald, Dawn Kingston, Hamideh Bayrampour, Suzanne Tough Mail
}

\begin{abstract}
Objective: Adverse childhood experiences (ACEs) are associated with poor health outcomes in adulthood. We developed a four category ACE risk profile variable using a domain-specific approach and examined ACEs as risk factors for diagnosed physical and mental health conditions.
\end{abstract}

Method: A computer-assisted telephone survey was conducted with a random sample of adults in Alberta, Canada. Eight questions were asked on adversity during childhood, based on the original ACE survey and modified to reflect the Canadian context and research methodology. Descriptive and multivariable analyses were conducted.

Results: Among the 1207 respondents, the majority were married or living common-law (65.8\%), had completed post-secondary education (78.2\%), and were Caucasian $(86.2 \%)$ with a mean age of 52.4 years $(\mathrm{SD}=16.3)$. Approximately one-third $(27.3 \%)$ experienced at least one type of abuse, and almost half (49.5\%) experienced at least one form of household dysfunction. ACEs were highly interrelated. Sixty-three percent fell into the low risk profile category, with the remaining 37\% divided among the three higher risk profile categories. Overall, the ACE risk profile variable was significantly associated with diagnosed mental health condition/addiction and chronic pain, controlling for sociodemographic characteristics.

Conclusion: The ACE risk profile category of adversity in both the abuse domain and the household dysfunction domain conferred the greatest risk for poor health outcomes in adulthood. Given the interrelated nature of ACEs, a more comprehensive approach to conceptualization of ACEs is warranted. Results have implications for prevention of ACEs and recovery from ACEs to decrease disease burden. Strategies may include effective programs to prevent exposure to toxic stress and support nurturing and stable relationships for children and families.

Keywords: Adverse Childhood Experiences; Population-based Survey; Canada; Chronic Pain; Mental Health Condition 


\section{INTRODUCTION}

There is growing documentation linking childhood traumatic experiences and poor physical and mental health outcomes later in life. Adverse Childhood Experiences (ACEs) include childhood trauma in the form of abuse, neglect, living in a home where there is violence, or having a mentally ill or substance abusing parent. Consistently, associations have been found between ACEs and unhealthy lifestyles, poor physical (e.g., heart disease, obesity) and mental health (e.g., suicide, addictions), and low educational achievement and economic productivity in adulthood ((Anda et al., 2006; Dong et al., 2004; Edwards, Holden, Felitti, \& Anda, 2003; Felitti et al., 1998; Hillis et al., 2004). Accumulating evidence suggests that early maltreatment and adversity can lead to stress-induced changes in a child's neurobiological systems early on with long lasting effects (McCrory, De Brito, \& Viding, 2010; Shonkoff, Boyce, \& McEwen, 2009). Indeed, the past decade has seen increasing research attention devoted to the neurobiological impact of early adversity with enhanced focus on neuroendocrine (e.g., hypothalamicpituitary-adrenal axis) responses, structural and functional changes in the brain, and the role of genetics and epigenetic effects associated with vulnerability and resilience (Hackman, Farah, \& Meaney, 2010; McCrory et al., 2010; Monk, Spicer, \& Champagne, 2012). Exposure to ACEs influences the stress response and coping strategies leading to health and social problems in adulthood (Dong et al., 2004; Douglas et al., 2010; Reiser, McMillan, Wright, \& Asmundson, 2014).

The original ACE study was conducted in the 1990's through collaboration between Kaiser Permanente and the Centres for Disease Control and Prevention (Felitti et al., 1998) to examine associations between childhood trauma and adult health outcomes. Categories of ACEs included childhood abuse (emotional, physical, sexual), neglect (emotional and physical), and household dysfunction (exposure to domestic violence, marital discord, and mentally ill, addicted, or criminal household members) experienced before the age of 18 years. Common conceptualizations of ACEs examine across studies comprise individual ACEs (e.g., physical abuse, parental addiction), ACE category/domain (experienced any abuse, experienced any household dysfunction), and ACE score.

Specific and cumulative approaches may oversimplify or overestimate ACEs as a risk factor for adult health outcomes, seriously compromising translation of findings into targeted interventions. For example, a cumulative approach, such as the ACE score, assumes equal weighting for ACEs and that any joint effects are additive. Specific approaches mask the interrelatedness of ACEs, and do not acknowledge existing evidence that the presence of one ACE significantly increases the likelihood of experiencing additional ACEs (Dong et al., 2004). Alternative, more comprehensive approaches to identify early risk profiles have been explored in the recent literature using latent variable approaches (Oliver, Kretschmer, \& Maughan, 2014), interactions (Lanza, Rhoades, Greenberg, \& Cox, 2011; Lanza, Rhoades, Nix, \& Greenberg, 2010), and a domain-specific approach for prenatal life stressors (Liu \& Tronick, 2013). We sought to extend the latter approach for ACEs to derive a domain-specific risk variable using data drawn from a population-based survey in Alberta, Canada. This approach 
incorporates aspects of both specific and cumulative risk to operationalize risk profile categories. We further sought to examine the association between the ACE domain-specific risk variable and diagnosed physical and mental health conditions in adulthood.

\section{METHOD}

\subsection{Survey instrument}

The Alberta Survey is an annual telephone survey of households across Alberta conducted by the Population Research Laboratory (PRL) at the University of Alberta. The survey varies yearly as different sponsors submit questions of interest. In 2013, the Alberta Centre for Child, Family and Community Research sponsored items designed to gather information on a history of adverse childhood experiences before the age of 18 years. The survey questions were based on the original ACE questionnaire used in the Adverse Childhood Experiences Study (ACE) Study (1995 - 1997), an American epidemiological study of over 17,000 individuals administered through Kaiser Permanente. The 2013 Alberta Survey ACE questions were slightly modified for brevity (e.g., yes/no responses) and wording to align with a telephone data collection methodology and to minimize response burden. In addition, an ACE that asked about growing up in a household in which someone experienced a chronic physical illness or disability was added to capture additional forms of adversity in childhood. An ACE on parental incarceration was not asked due to its rarity in the Alberta context, confirmed by provincial adult incarceration rates (Statistics Canada, 2012). Domains of abuse and household dysfunction were covered. Questions on adult perceived psychosocial and physical health status and 11 diagnosed health conditions in adulthood (yes/no), including mental health and substance abuse were also asked. Tables 1 and 2 provide description of ACEs and adult health indicators, respectively. Additional components of the survey included a standardized introduction and demographic questions that were replicated from the 2012 Alberta Survey, administered by trained interviewers in order to build and establish rapport over the telephone. The voluntary nature of participation and confidentiality of responses were confirmed prior to the interview. All questions were pre-tested by the PRL on 20 households to check wording, response categories, question order, interviewer instructions, and length of interview (Population Research Laboratory, 2013). Following the pre-test, only slight modifications to question wording were made. Although the Alberta ACE survey was not validated per se, adequate reliability and construct validity has been shown for the original ACE checklist (Dube, Williamson, Thompson, Felitti, \& Anda, 2004; Edwards et al., 2001). 
Table 1. Adverse childhood events (ACEs) indicator questions and conceptualizations Alberta Adverse Childhood Experiences Survey 2013

\begin{tabular}{|l|l|}
\hline Indicator & \multicolumn{1}{|c|}{ Question/Categories } \\
\hline Abuse & $\begin{array}{l}\text { "Did you frequently experience verbal insults or threats from an } \\
\text { adult or parent in the household?" }\end{array}$ \\
\hline Physical abuse & $\begin{array}{l}\text { "Were you ever injured or bruised from physical abuse by an } \\
\text { adult or parent in the household?" } \\
\text { "Did you experience inappropriate sexual advances or contact } \\
\text { by an adult or someone who was 5 or more years older than } \\
\text { you?" }\end{array}$ \\
\hline Sexual abuse & "Did you ever witness your mother or stepmother being treated \\
violently?"
\end{tabular}

Table 2. Adult health diagnostic indicator questions and conceptualizations - Alberta Adverse Childhood Experiences Survey 2013

\begin{tabular}{|l|l|}
\hline Indicator & \multicolumn{1}{c|}{ Question/Categories } \\
\hline Physical Health & $\begin{array}{l}\text { "Have you been diagnosed with any of the following health } \\
\text { problems as an adult?" }\end{array}$ \\
\hline & High Blood Pressure \\
\hline & Diabetes \\
\hline & Irritable Bowel Syndrome/Crohn's disease \\
\hline & Chronic Pain \\
\hline
\end{tabular}




\begin{tabular}{|l|l|}
\hline & Backache \\
\hline & Asthma \\
\hline Mental Health & Allergies \\
\hline & Chronic fatigue syndrome/ fibromyalgia \\
\hline Substance Abuse & Anxiety Disorders \\
\hline \begin{tabular}{l} 
MDD (Major Depressive Disorder) \\
\hline $\begin{array}{l}\text { Conceptualizations of } \\
\text { Diagnosed health conditions }\end{array}$
\end{tabular} & Alcohol dependency problems \\
\hline $\begin{array}{l}\text { Mental health condition/Addiction } \\
\text { (Anxiety, depression, other mental } \\
\text { health problems/alcohol or drug } \\
\text { dependence) }\end{array}$ & $\begin{array}{l}\text { Yes } \\
\text { No }\end{array}$ \\
\hline $\begin{array}{l}\text { Circulatory condition (High blood } \\
\text { pressure, cardiovascular disease, } \\
\text { stroke, diabetes) }\end{array}$ & $\begin{array}{l}\text { Yes } \\
\text { No }\end{array}$ \\
\hline $\begin{array}{l}\text { Respiratory condition (Lung or } \\
\text { asthma problems) }\end{array}$ & $\begin{array}{l}\text { Yes } \\
\text { No }\end{array}$ \\
\hline $\begin{array}{l}\text { Chronic pain condition (Chronic } \\
\text { fatigue syndrome, fibromyalgia, } \\
\text { chronic back or joint pain) }\end{array}$ & $\begin{array}{l}\text { Yes } \\
\text { No }\end{array}$ \\
\hline
\end{tabular}

\subsection{Survey procedures}

Random-digit dialing of several provincial telephone banks generated a random sample of households across rural and urban areas and ensured that the sampling frame included households with and without telephone directory listings (Population Research Laboratory, 2013). Respondents were eligible to participate if they were: 1) $\geq 18$ years; and 2) contacted by direct dialing. Cell phone numbers were included if they were available in any provincial telephone bank. The study protocol was approved by the Research Ethics Board at the University of Alberta. Data were collected between June 18, 2013 and July 23, 2013 by trained PRL interviewers using computer-assisted telephone interviews. A random sample of
$10 \%$ of the respondents was followed-up by PRL supervisors to verify accuracy of data collection. Interviews were conducted in English and each lasted a maximum of 30 minutes.

\subsection{Study variables \\ 2.3.1 Adverse childhood experiences}

A single ACE risk profile variable was developed using a domain-specific approach (Liu, 2013) that considered both ACE score and two main domains: abuse and household dysfunction. The abuse domain comprised three ACE items: physical abuse, sexual abuse, and emotional abuse.

The household dysfunction domain was composed of five ACE items: witnessed domestic violence; growing up with a mentally ill household member; 
growing up with an addicted household member; chronic physical illness in household; and parental separation. We defined high and low risk within each domain according to cut-off scores. Cut-off scores were determined based on the number of components within each domain. For abuse, high risk was defined as reporting at least one ACE. For household dysfunction, at least 2 ACEs were considered high risk. These cut-offs were designed to ensure that categories did not simply reflect a greater number of ACEs. Since each individual could be either high or low on each domain, a single variable with four profiles was derived: (1) low risk abuse, low risk household dysfunction; (2) low risk abuse, high risk household dysfunction; (3) high risk abuse, low risk household dysfunction; (4) high risk abuse, high risk household dysfunction.

\subsubsection{Adult health outcomes}

Given small cell sizes for individual diagnosed adult health conditions, we combined similar medical conditions based on clinical considerations and correlational analysis. Four grouped health conditions were derived: mental health condition/addiction; circulatory condition; respiratory condition; and chronic pain.

\subsection{Analysis}

Descriptive data were generated to describe sample characteristics, ACEs, and adult health outcomes as frequencies and percentages. Continuous variables were described using means (SD) or medians (IQR). Bivariate and logistic multivariable analyses were performed to examine the relationship between the four-category
ACE risk profile variable (lowest risk profile taken as the reference group) and each of the grouped diagnosed health conditions. An alpha level of less than 0.05 was considered statistically significant. Multivariable analysis controlled for sociodemographic variables, including, age, household income, employment status, education, marital status, number of children in household, community type, Canadian born, ethnicity, and gender. Multivariable results are presented as odds ratios (ORs) and $95 \%$ confidence intervals (CIs). The analysis was conducted using SPSS (Version 20.0).

\section{RESULTS}

Of the 5786 adults screened, 4579 refused or were incomplete and 1207 completed interviews were conducted (20.9\% response rate) with 612 females and 595 males, as per a balanced gender design. Approximately two-thirds of the sample lived in urban regions with onethird in rural areas, reflecting the distribution of the Alberta population. The mean age of the respondents was 52.4 years $(\mathrm{SD}=16.3)$. The majority of respondents were married or living common-law (65.8\%), had completed postsecondary education $(78.2 \%)$, were born in Canada $(80.1 \%)$, and were Caucasian $(86.2 \%)$. Over half of the respondents were employed either full-time or part-time $(55.7 \%)$. Almost three-quarters of households had no children in the household (70.8\%) (Table 3). 
Table 3. Socio-demographic characteristics of respondents of the 2013 Alberta Survey $\left(\mathrm{n}=1207^{\mathrm{a}}\right)$

\begin{tabular}{|c|c|}
\hline Demographic Characteristics & $\mathrm{n}(\%)$ \\
\hline \multicolumn{2}{|l|}{ Gender } \\
\hline Male & $595(49.3)$ \\
\hline Female & $612(50.7)$ \\
\hline \multicolumn{2}{|l|}{ Community type } \\
\hline Rural & $404(33.5)$ \\
\hline Urban & $803(66.5)$ \\
\hline \multicolumn{2}{|l|}{ Marital Status } \\
\hline Married/Common-Law & $791(65.8)$ \\
\hline Single/Divorced/Separated/Widowed & $411(34.2)$ \\
\hline \multicolumn{2}{|l|}{ Education } \\
\hline Less than High School & $77(6.5)$ \\
\hline High School Complete & $184(15.4)$ \\
\hline Post Secondary & $936(78.2)$ \\
\hline \multicolumn{2}{|l|}{ Born in Canada } \\
\hline Yes & $965(80.1)$ \\
\hline No & $240(19.9)$ \\
\hline \multicolumn{2}{|l|}{ Ethnicity } \\
\hline Caucasian & $1028(86.2)$ \\
\hline Other & $165(13.8)$ \\
\hline \multicolumn{2}{|l|}{ Employment status } \\
\hline Employed full-time (30 or more hours/week) & $552(45.8)$ \\
\hline Employed part-time (less than 30 hours/week) & $119(9.9)$ \\
\hline Student & $40(3.3)$ \\
\hline Other (unemployed, retired, homemaker, maternity leave, on disability, etc.) & $494(41.0)$ \\
\hline \multicolumn{2}{|l|}{ Total Household income (before taxes and deductions) } \\
\hline$\$ 39,999$ or less & $159(16.1)$ \\
\hline$\$ 40,000$ or more & $825(83.9)$ \\
\hline \multicolumn{2}{|l|}{ Number of children under 18 in household } \\
\hline 0 & $854(70.8)$ \\
\hline 1 & $141(11.7)$ \\
\hline 2 or more & $211(17.5)$ \\
\hline Age (Mean (SD)) & $52.43(16.34)$ \\
\hline
\end{tabular}

${ }^{\mathrm{a}}$ Denominator varies due to missing data for some variables

Ninety-seven percent $(n=1169)$ of respondents answered all eight ACE questions. Before the age of 18 , almost a third of participants $(27.2 \%)$ experienced at least one type of abuse, and nearly half experienced at least one form of household dysfunction (49.1\%). Prevalences of individual ACEs ranged from a low of $11 \%$ for physical abuse to a high of $20 \%$ for either household substance abuse or Copyright (C) 2015, Knowledge Enterprises Incorporated. All rights reserved. mental illness in household. Just under half reported zero ACEs (44.2\%), 35.8\% reported 1-2 ACEs, and $20.0 \%$ reported 3 or more ACEs. Sixty-three percent fell into the low risk profile category, defined as low risk abuse and low risk household dysfunction, with the remaining $37 \%$ divided among the three higher risk profile categories (Table 4). 
Table 4. Summary of participant responses to ACE items and different conceptualizations of ACEs in the 2013 Alberta Survey $\left(n=1169^{\mathrm{a}}\right)$

\begin{tabular}{|c|c|}
\hline ACE & $\mathrm{n}(\%)$ \\
\hline \multicolumn{2}{|l|}{ Abuse } \\
\hline \multicolumn{2}{|l|}{ Emotional abuse } \\
\hline Yes & $198(16.9)$ \\
\hline No & $971(83.1)$ \\
\hline \multicolumn{2}{|l|}{ Physical abuse } \\
\hline Yes & $128(11.0)$ \\
\hline No & $1041(89.0)$ \\
\hline \multicolumn{2}{|l|}{ Sexual abuse } \\
\hline Yes & $174(14.9)$ \\
\hline No & $995(85.1)$ \\
\hline \multicolumn{2}{|l|}{ Household dysfunction } \\
\hline \multicolumn{2}{|l|}{ Domestic violence } \\
\hline Yes & $153(13.1)$ \\
\hline No & $1016(86.9)$ \\
\hline \multicolumn{2}{|l|}{ Household substance abuse } \\
\hline Yes & $242(20.7)$ \\
\hline No & $927(79.3)$ \\
\hline \multicolumn{2}{|l|}{ Mental illness in household } \\
\hline Yes & $241(20.6)$ \\
\hline No & $928(79.4)$ \\
\hline \multicolumn{2}{|l|}{ Chronic physical illness in household } \\
\hline Yes & $190(16.3)$ \\
\hline No & $979(83.7)$ \\
\hline \multicolumn{2}{|l|}{ Parental separation or divorce } \\
\hline Yes & $205(17.6)$ \\
\hline No & $964(82.4)$ \\
\hline \multicolumn{2}{|l|}{ Conceptualizations of ACE } \\
\hline \multicolumn{2}{|l|}{ Any abuse } \\
\hline Yes & $318(27.2)$ \\
\hline No & $851(72.8)$ \\
\hline \multicolumn{2}{|l|}{ Any household dysfunction } \\
\hline Yes & $574(49.1)$ \\
\hline No & $595(50.9)$ \\
\hline \multicolumn{2}{|l|}{ ACE score (categorical) } \\
\hline 0 & $517(44.2)$ \\
\hline $1-2$ & $418(35.8)$ \\
\hline$\geq 3$ & $234(20.0)$ \\
\hline \multicolumn{2}{|l|}{ ACE risk profile } \\
\hline Low risk abuse \& low risk household dysfunction & $736(63.0)$ \\
\hline Low risk abuse \& high risk household dysfunction & $115(9.8)$ \\
\hline High risk abuse \& low risk household dysfunction & $161(13.8)$ \\
\hline High risk abuse \& high risk household dysfunction & $157(13.4)$ \\
\hline
\end{tabular}

${ }^{\text {a }}$ Provided a valid response for all 8 ACEs 
ACEs were highly interrelated. When a respondent was exposed to $1 \mathrm{ACE}$, the probability of exposure to additional ACEs was increased. The median probability of exposure to any additional
ACE given having experienced the first was $84.0 \%$. For any 2 and 3 additional ACEs, the median probability was $64.2 \%$ and $44.1 \%$, respectively (Table 5 ).

Table 5. Prevalence of each adverse childhood experience and reporting of additional ACEs

\begin{tabular}{|c|c|c|c|c|c|c|c|c|c|c|}
\hline \multirow{3}{*}{$\begin{array}{l}\text { Adverse childhood } \\
\text { experience }\end{array}$} & \multirow{3}{*}{$\mathrm{n}$} & \multirow{3}{*}{$\begin{array}{c}\text { Prevalence } \\
(\%)\end{array}$} & \multicolumn{8}{|c|}{ Additional ACES } \\
\hline & & & \multicolumn{2}{|c|}{0} & \multicolumn{2}{|c|}{$\geq 1$} & \multicolumn{2}{|c|}{$\geq 2$} & \multicolumn{2}{|c|}{$\geq 3$} \\
\hline & & & $\mathrm{n}$ & $\%$ & $\mathrm{n}$ & $\%$ & $\mathrm{n}$ & $\%$ & $\mathrm{n}$ & $\%$ \\
\hline \multicolumn{11}{|l|}{ Abuse } \\
\hline Emotional abuse & 198 & 16.9 & 18 & 9.0 & 180 & 91.0 & 151 & 76.2 & 110 & 55.5 \\
\hline Physical abuse & 128 & 11.0 & 9 & 6.9 & 119 & 93.1 & 107 & 83.7 & 85 & 66.4 \\
\hline Sexual abuse & 174 & 14.9 & 33 & 19.0 & 141 & 81.0 & 110 & 63.1 & 75 & 43.0 \\
\hline \multicolumn{11}{|l|}{$\begin{array}{l}\text { Household } \\
\text { dysfunction }\end{array}$} \\
\hline Domestic violence & 153 & 13.1 & 8 & 5.2 & 145 & 94.8 & 122 & 79.8 & 99 & 64.8 \\
\hline $\begin{array}{l}\text { Household substance } \\
\text { abuse }\end{array}$ & 242 & 20.7 & 37 & 15.3 & 205 & 84.7 & 158 & 65.2 & 109 & 45.1 \\
\hline $\begin{array}{l}\text { Mental illness in } \\
\text { household }\end{array}$ & 241 & 20.6 & 40 & 16.7 & 201 & 83.3 & 151 & 62.6 & 103 & 42.7 \\
\hline $\begin{array}{l}\text { Physical illness in } \\
\text { household }\end{array}$ & 190 & 16.3 & 79 & 41.6 & 111 & 58.4 & 77 & 40.4 & 51 & 26.8 \\
\hline $\begin{array}{l}\text { Parental separation or } \\
\text { divorce }\end{array}$ & 205 & 17.6 & 47 & 23.0 & 158 & 77.0 & 117 & 57.0 & 79 & 38.6 \\
\hline Median & & & & 16.0 & & 84.0 & & 64.2 & & 44.1 \\
\hline Range & & & & $\begin{array}{l}5.2- \\
41.6\end{array}$ & & $\begin{array}{l}58.4- \\
94.8\end{array}$ & & $\begin{array}{l}40 .- \\
83.7\end{array}$ & & $\begin{array}{r}26.8- \\
66.4\end{array}$ \\
\hline
\end{tabular}

Among those who answered all eight ACE questions, proportions reporting a diagnosed health condition in adulthood were $15 \%, 32.1 \%, 27.0 \%$, and $20.2 \%$ for mental health condition/addiction, circulatory condition, respiratory condition, and chronic pain, respectively (Table 6). Multivariable results showed that the ACE risk profile variable was significantly associated with diagnosed mental health condition/addiction and chronic pain, controlling for sociodemographic characteristics.
Compared to the lowest risk profile category, the risk profile category with at least one ACE per domain conferred the greatest risk for both outcomes. There was no evidence for an association between the ACE risk profile variable and the remaining diagnosed health conditions in multivariable analysis. Adjusted ORs for ACE risk profile categories and covariates for each diagnosed health condition are reported in Table 7. Unadjusted ORs for ACE categories are presented for comparative purposes. 
Table 6. Diagnosed health conditions among adults in the 2013 Alberta Survey $\left(n=1169^{\mathrm{a}}\right)$

\begin{tabular}{|l|c|}
\hline Diagnosed health conditions & $\mathrm{n}(\%)^{\mathrm{c}}$ \\
\hline $\begin{array}{l}\text { Mental health condition/Addiction (Anxiety, depression, other mental } \\
\text { health problems/alcohol or drug dependence) }\end{array}$ & $174(15.0)$ \\
\hline $\begin{array}{l}\text { Circulatory condition (High blood pressure, cardiovascular disease, } \\
\text { stroke, diabetes) }\end{array}$ & $372(32.1)$ \\
\hline Respiratory condition (Lung or asthma problems) & $314(27.0)$ \\
\hline $\begin{array}{l}\text { Chronic pain condition (Chronic fatigue syndrome, fibromyalgia, } \\
\text { chronic back or joint pain) }\end{array}$ & $235(20.2)$ \\
\hline
\end{tabular}

${ }^{a}$ Provided a valid response for all 8 ACEs

${ }^{\mathrm{b}}$ Individual health conditions are not mutually exclusive

${ }^{c}$ Denominator $n=1161$ due to missing data

Table 7. Multivariable logistic regression models for diagnosed adult health outcomes

\begin{tabular}{|l|c|c|c|c|}
\hline $\begin{array}{l}\text { ACE risk profile } \\
\text { category }\end{array}$ & $\begin{array}{c}\text { Mental health } \\
\text { condition/Addic } \\
\text { tion }\end{array}$ & $\begin{array}{c}\text { Circulatory } \\
\text { condition }\end{array}$ & $\begin{array}{c}\text { Respiratory } \\
\text { condition }\end{array}$ & $\begin{array}{c}\text { Chronic pain } \\
\text { condition }\end{array}$ \\
\hline $\begin{array}{l}\text { Low risk abuse, high } \\
\text { risk household } \\
\text { dysfunction } \\
\text { aOR (95\% CI) } \\
\text { uOR (95\% CI) }\end{array}$ & $2.64(1.49,4.67)$ & $1.18(0.69,2.02)$ & $1.53(0.96,2.44)$ & $3.22(1.91,5.42)$ \\
\hline $\begin{array}{l}\text { High risk abuse, low } \\
\text { risk household } \\
\text { dysfunction }\end{array}$ & $0.89(0.58,1.37)$ & $1.44(0.93,2.22)$ & $2.76(1.73,4.39)$ \\
\hline $\begin{array}{l}\text { aOR (95\% CI) } \\
\text { uOR (95\% CI) }\end{array}$ & $3.20(1.94,5.28)$ & $0.85(0.541 .34)$ & $1.30(0.86,1.96)$ & $3.02(1.92,4.74)$ \\
\hline $\begin{array}{l}\text { High risk abuse and } \\
\text { high risk household } \\
\text { dysfunction }\end{array}$ & $3.41(2.18,5.34)$ & $1.04(0.72,1.49)$ & $1.46(0.99,2.12)$ & $3.09(2.07,4.62)$ \\
\hline $\begin{array}{l}\text { aOR (95\% CI) } \\
\text { uOR (95\% CI) }\end{array}$ & $4.13(2.53,6.74)$ & $1.04(0.651 .67)$ & $1.66(1.10,2.51)$ & $5.19(3.31,8.14)$ \\
\hline $\begin{array}{l}\text { Omnibus p-value for } \\
\text { ACE risk profile } \\
\text { variable (adjusted } \\
\text { modelb) }\end{array}$ & $4.70(3.06,7.24)$ & $0.99(0.68,1.43)$ & $2.31(1.61,3.32)$ & $4.90(3.33,7.21)$ \\
\hline
\end{tabular}

${ }^{\text {a. }}$ Reference group: Low risk abuse, low risk household dysfunction

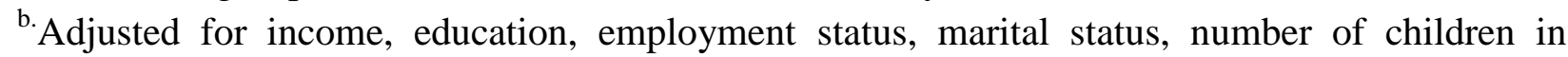
household, born in Canada, ethnicity, community type, gender, and age.

\section{DISCUSSION}

To our knowledge, this is one of the few population-based studies in Canada and the only one in Alberta to describe the general public's exposure to adverse childhood experiences and their association to diagnosed health outcomes in adulthood. Key findings indicate that a risk profile of at least one $\mathrm{ACE}$ in the abuse domain and at least two ACEs in the household dysfunction domain confers the greatest risk for poor adult health outcomes, compared to risk profiles in which ACEs are clustered within a domain. This increased risk was identified specifically for diagnosed mental health conditions/addiction and conditions of 
chronic pain. In addition, this study aligns with previous research that documents the high interrelatedness of ACEs, providing justification for conceptualizing ACEs in a more comprehensive manner than simpler approaches such as by individual ACEs or total ACE score. Taken together, the results from this study suggest that there may be a toxic threshold effect of at least three ACEs across both domains.

Previous research has reported varying prevalence rates for individual ACEs. For example, Anda and colleagues (2006) using the original ACE study data, reported the following rates: $10.6 \%$ for emotional abuse, $28.3 \%$ for physical abuse, $20.7 \%$ for sexual abuse, $26.9 \%$ for household substance abuse, $19.4 \%$ for household mental illness, $12.7 \%$ for domestic violence, and $23.3 \%$ for parental separation or divorce. Another study reported rates of childhood physical abuse at $26 \%$ and childhood sexual abuse at $9 \%$ (Chartier, Walker, \& Naimark, 2010). The proportions found in the present study align with recently reported Canadian statistics (Afifi et al., 2014; Langlois \& Garner, 2013). An analysis of the National Population Health Survey in Canada revealed that $19.4 \%$ of adults reported parental addiction in childhood and $11.5 \%$ experienced childhood physical abuse (Langlois \& Garner, 2013). Corresponding rates in the current study were $20.7 \%$ and $11.0 \%$. Similarly, the rate of 'any abuse' in the current study $(27.2 \%)$ parallels that of $32 \%$ for any child abuse reported in the 2012 Canadian Community Health Survey: Mental Health (Afifi et al., 2014). Although discrepancies in individual rates have been reported, taken together it is clear that adverse childhood experiences are common and this is true across different populations, samples, study designs, and methodologies.

Co-occurrence of ACES in the present study aligns with the study by Dong and colleagues (2004) using data drawn from the original ACE study. The authors reported that two-thirds of participants reported at least one ACE; in our study, the proportion was slightly lower at $56 \%$. Of note, the original ACE study covered 10 categories of ACEs, while ours covered eight. Similar results were obtained regarding the probabilities of exposure to additional ACEs given exposure to the first, and for any two and three additional ACEs, suggesting that exposure to multiple ACEs is common. For example, in the study by Dong and colleagues (2004), if a participant had experienced one category of ACE, 86.5\% reported having been exposed to at least one additional ACE; the corresponding proportion in our study was $84 \%$. Probabilities decreased for at least two or at least three more additional exposures in both studies.

The association between childhood adversity and mental health and addiction issues later in life has been consistently documented in the literature (Douglas et al., 2010; Dube et al., 2003; Edwards et al., 2003; Felitti et al., 1998; Kessler et al., 2010). A recent Canadian study using population-based data sources found a strong association between retrospectively and prospectively assessed childhood adversities and major depression, but not excessive alcohol consumption in adulthood (Patten et al., 2014). Discrepancies could be due to operationalization of both childhood adversities and substance use across studies. Similar to the present study, Patten and colleagues (2014) also found associations for painful conditions in 
adulthood. Given that painful medical conditions are strongly correlated with major depression (Patten et al., 2005), it is possible that the association found in the present study was simply a reflection of the association with mental health conditions, specifically depression. In an attempt to disentangle this issue, we examined the extent to which painful conditions and major depression were correlated, as well as the association between ACEs and chronic pain condition among those adults without diagnosed major depressive disorder. Although the two adult health conditions were significantly associated $(\mathrm{p}<0.001)$, the association between ACEs and chronic pain condition was robust even among those without co-morbid major depressive disorder (results not shown). This finding is important given limited and often speculative evidence between childhood adversity and painful conditions in adulthood (Raphael, Chandler, \& Ciccone, 2004). A more comprehensive test of mediation could not be examined given that the temporal order of diagnoses was not assessed, although upon examination of ACE risk profile for chronic pain adjusting for mental health condition and for mental health condition controlling for chronic pain, the ACE risk profile ORs were attenuated. Further research considering timing of diagnoses would be informative.

Some conceptual shortcomings may arise in common approaches for ACE risk as seen in previous studies. In particular, the specific stressor approach and the cumulative risk hypothesis may oversimplify and misrepresent the association between ACEs and poor adult health outcomes. Given that ACEs rarely occur in isolation, it is ineffectual to consider them separately when predicting risk. Simple summation of ACEs assumes that each ACE has the same effect on the outcome, which may be unrealistic. Compared to a cumulative approach, our domain-specific

risk approach relied on low thresholds for high risk; however, this strategy ensured that the domain-specific ACE risk factor did not simply reflect more ACEs. Exposure to trauma across abuse and household dysfunction domains may overtax an individual's coping and stress response in a domain. Further, a child may not have an opportunity for a 'safe haven' when adversity crosses different domains. Brain research helps us to understand this relationship: the toxic stress from trauma damages the structure and function of the developing brain (Garner \& Shonkoff, 2012). Safe, supportive and nurturing environments can mitigate the effects of toxic stress; however, the absence of these foundations may permanently alter regulation of the stress response system, immunologic responsiveness, effective self-regulation and early establishment of health-promoting behaviours (McEwen, 2012) .

The ACE risk profile variable was associated with only 2 of the 4 diagnosed conditions; this was somewhat surprising given established links with a range of diagnosed conditions reported in previous studies (Anda et al., 2006; Chapman et al., 2004; Dube et al., 2003; Springer, Sheridan, Kuo, \& Carnes, 2007). However, the association between early trauma and mental health problems and chronic pain may be mediated by the same biological mechanism involving upregulation of the immune system. A recent review demonstrated that communications between the central nervous system and biological mediators of the inflammatory 
response induce neural and behavioural alterations that manifest as depressive symptoms (Slavich \& Irwin, 2014); increasing evidence also suggest elevated levels of inflammation drives increased sensitivity to pain leading to chronic pain (Marchand, Perretti, \& McMahon, 2005; Slavich \& Irwin, 2014; Wu et al., 2005). A common underlying biological process involving inflammation as a result of early life stress is one potential explanation for the results in the present study (Danese \& McEwen, 2012). Unknowns such as timing of diagnosis, chronicity of ACEs over time, and experiences of other adversities such as poverty, social isolation, and other life stressors, underscore the complexities in explaining how early trauma translates into disease outcomes later in life. In addition, many other factors may mitigate or exacerbate outcomes among those who were exposed to adversities during childhood. There rarely is a direct causal pathway leading to a particular outcome (Wolfe, Crooks, Lee, McIntyre- Smith, \& Jaffe, 2003). Likely, a number of specific and common underlying pathways exist and additional research is needed to examine co-morbidity hypotheses and other issues such as moderating effects.

Study limitations include the low response rate and therefore potential threats to both internal and external validity, yet the $20 \%$ response rate is common in studies that use telephone surveys and past Alberta surveys (Kingston et al., 2014). Further, the sample characteristics, in general, reflect the demographic profile of the province, in terms of sociodemographic and socioeconomic characteristics (Statistics Canada, 2012), with the exception that respondents of the Alberta survey were older. However, this may lend itself to robustness of the findings, especially in terms of validity for the diagnosed conditions as many do not emerge until later in life. If we assume that nonrespondents were more likely to report both ACEs and poor adult health outcomes, our results may underestimate the association of ACE risk on diagnosed conditions in adulthood. Finally, the results may be less generalizable to young families, given that the majority of respondents did not have children in the household at the time of the survey. Overall, the consistency in the prevalence of exposures with other ACE research provides reassurance about the validity of these findings.

The potential for recall bias and differential misclassification due to retrospective reporting of ACEs is also a study limitation. However, Patten and colleagues (2014) demonstrated that method of assessment of childhood adversity (retrospective vs. prospective) did not significantly affect associations with adult health outcomes. The authors noted that the potential for bias may depend on the health outcome under study; for example adults with major depression may tend to overestimate childhood adversity (Patten et al., 2014). On the other hand, reports of childhood adversity may be underreported as demonstrated in some longitudinal follow-up studies of adults who experienced child abuse (Della Femina, Yeager, \& Lewis, 1990; Williams, 1995), which in turn would bias our findings to the null. To further explore the former, we fit three additional models for circulatory condition, respiratory condition, and chronic pain, controlling for diagnosed depression or anxiety. In general, results were robust in these models, which suggest that reporting bias 
due to a mental health condition was unlikely; however, a better approach to explore the possibility for reporting bias would have used current symptomatology, which was unavailable in the present study.

The results of this study have implications for prevention of ACEs and recovery from ACEs to decrease the burden of disease. Prevention strategies may include effective programs and interventions to stop child maltreatment and foster safe environments that support nurturing and stable relationships for children and families. Co-occurrence of adverse experiences is important to consider when identifying and treating children who have been exposed to any one type of maltreatment. Interventions that target children and families who are already exposed to adverse childhood events can involve supportive interventions that may be short or long-term, individual or group-based, formal or informal. Further, interventions should be individualistically responsive the child's familial context focusing on minimizing disruption and stabilizing the environment (Holt, Buckley, \& Whelan, 2008). A commitment to social change is also needed to address root causes and the social determinants of health like poverty, lack of stable housing, and lack of social support (Shonkoff et al., 2009).

\section{ACKNOWLEDGEMENTS}

We are extremely grateful to the Albertan adults who took part in this study and the Population Research Laboratory of Alberta. Funding for this study was provided through a partnership between the Alberta Centre for Child, Family, and Community Research and the Norlien Foundation. 


\section{REFERENCES}

Afifi, T. O., MacMillan, H. L., Boyle, M., Taillieu, T., Cheung, K., \& Sareen, J. (2014). Child abuse and mental disorders in Canada. CMAJ., 186(9), E324332. doi: 310.1503/cmaj.131792. Epub 132014 Apr 131722.

Anda, R. F., Felitti, V. J., Bremner, J. D., Walker, J. D., Whitfield, C., Perry, B. D., .. . Giles, W. H. (2006). The enduring effects of abuse and related adverse experiences in childhood. A convergence of evidence from neurobiology and epidemiology. Eur Arch Psychiatry Clin Neurosci., 256(3), 174-186. Epub 2005 Nov 2029.

Chapman, D. P., Whitfield, C. L., Felitti, V. J., Dube, S. R., Edwards, V. J., \& Anda, R. F. (2004). Adverse childhood experiences and the risk of depressive disorders in adulthood. J Affect Disord., 82(2), 217-225.

Chartier, M. J., Walker, J. R., \& Naimark, B. (2010). Separate and cumulative effects of adverse childhood experiences in predicting adult health and health care utilization. Child Abuse Negl., 34(6), 454-464. doi: 410.1016/j.chiabu.2009.1009.1020. Epub 2010 Apr 1020.

Danese, A., \& McEwen, B. S. (2012). Adverse childhood experiences, allostasis, allostatic load, and age-related disease. Physiol Behav., 106(1), 29-39. doi: $\quad$ 10.1016/j.physbeh.2011.1008.1019. Epub 2011 Aug 1025.

Della Femina, D., Yeager, C. A., \& Lewis, D. O. (1990). Child abuse: adolescent records vs. adult recall. Child
Abuse Negl, 14(2), 227-231.

Dong, M., Anda, R. F., Felitti, V. J., Dube, S. R., Williamson, D. F., Thompson, T. J., . . . Giles, W. H. (2004). The interrelatedness of multiple forms of childhood abuse, neglect, and household dysfunction.

Child Abuse Negl., 28(7), 771-784.

Douglas, K. R., Chan, G., Gelernter, J., Arias, A. J., Anton, R. F., Weiss, R. D., . . Kranzler, H. R. (2010). Adverse childhood events as risk factors for substance dependence: partial mediation by mood and anxiety disorders. Addict Behav., 35(1), 7-13. doi: 10.1016/j.addbeh.2009.1007.1004. Epub 2009 Aug 1018.

Dube, S. R., Felitti, V. J., Dong, M., Chapman, D. P., Giles, W. H., \& Anda, R. F. (2003). Childhood abuse, neglect, and household dysfunction and the risk of illicit drug use: the adverse childhood experiences study. Pediatrics., 111(3), 564-572.

Dube, S. R., Williamson, D. F., Thompson, T., Felitti, V. J., \& Anda, R. F. (2004) . Assessing the reliability of retrospective reports of adverse childhood experiences among adult HMO members attending a primary care clinic. Child Abuse Negl, 28(7), 729-737. doi: 10.1016/j.chiabu.2003.08.009

Edwards, V. J., Anda, R. F., Nordenberg, D. F., Felitti, V. J., Williamson, D. F., \& Wright, J. A. (2001). Bias assessment for child abuse survey: factors affecting probability of response to a survey about childhood abuse. Child Abuse Negl, 25(2), 307-312. 
Edwards, V. J., Holden, G. W., Felitti, V. J., \& Anda, R. F. (2003). Relationship between multiple forms of childhood maltreatment and adult mental health in community respondents: results from the adverse childhood experiences study. Am J Psychiatry., 160(8), 14531460.

Felitti, V. J., Anda, R. F., Nordenberg, D., Williamson, D. F., Spitz, A. M., Edwards, V., . . . Marks, J. S. (1998). Relationship of childhood abuse and household dysfunction to many of the leading causes of death in adults. The Adverse Childhood Experiences (ACE) Study. Am J Prev Med., 14(4), 245-258.

Garner, A. S., \& Shonkoff, J. P. (2012). Early childhood adversity, toxic stress, and the role of the pediatrician: translating developmental science into lifelong health. Pediatrics., 129(1), e224231. doi: 210.1542/peds.2011-2662. Epub 2011 Dec 1526.

Hackman, D. A., Farah, M. J., \& Meaney, M. J. (2010). Socioeconomic status and the brain: mechanistic insights from human and animal research. Nat Rev Neurosci., 11(9), 651-659. doi: $610.1038 /$ nrn2897.

Hillis, S. D., Anda, R. F., Dube, S. R., Felitti, V. J., Marchbanks, P. A., \& Marks, J. S. (2004). The association between adverse childhood experiences and adolescent pregnancy, long-term psychosocial consequences, and fetal death. Pediatrics., 113(2), 320-327.

Holt, S., Buckley, H., \& Whelan, S. (2008). The impact of exposure to domestic violence on children and young people: a review of the literature. Child
Abuse Negl., 32(8), 797-810. doi: 710.1016/j.chiabu.2008.1002.1004. Epub 2008 Aug 1026.

Kessler, R. C., McLaughlin, K. A., Green, J. G., Gruber, M. J., Sampson, N. A., Zaslavsky, A. M., . . .Williams, D. R. (2010). Childhood adversities and adult psychopathology in the WHO World Mental Health Surveys. Br J Psychiatry., 197(5), 378-385.

doi: 310.1192/bjp.bp.1110.080499.

Kingston, D., McDonald, S., Tough, S., Austin, M. P., Hegadoren, K., \& Lasiuk, G. (2014). Public views of acceptability of perinatal mental health screening and treatment preference: a population based survey. BMC Pregnancy Childbirth., 14:67.(doi), 10.1186/14712393-1114-1167.

Langlois, K. A., \& Garner, R. (2013). Trajectories of psychological distress among Canadian adults who experienced parental addiction in childhood. Health Rep., 24(3), 14-21.

Lanza, S. T., Rhoades, B. L., Greenberg, M. T., \& Cox, M. (2011). Modeling multiple risks during infancy to predict quality of the caregiving environment: contributions of a personcentered approach. Infant Behav Dev., 34(3), 390-406. doi: 310.1016/j.infbeh.2011.1002.1002. Epub 2011 Apr 1017.

Lanza, S. T., Rhoades, B. L., Nix, R. L., \& Greenberg, M. T. (2010). Modeling the interplay of multilevel risk factors for future academic and behavior problems: a person-centered approach. Dev Psychopathol., 22(2), 313-335. doi: $310.1017 /$ S0954579410000088. 
Liu, C. H., \& Tronick, E. (2013). Reconceptualising prenatal life stressors in predicting post-partum depression: cumulative-, specific-, and domain-specific approaches to calculating risk. Paediatr Perinat Epidemiol., 27(5), 481-490. doi: 410.1111/ppe.12072.

Marchand, F., Perretti, M., \& McMahon, S. B. (2005). Role of the immune system in chronic pain. Nat Rev Neurosci., 6(7), 521-532.

McCrory, E., De Brito, S. A., \& Viding, E. (2010). Research review: the neurobiology and genetics of maltreatment and adversity. J Child Psychol Psychiatry., 51(10), 1079-1095. doi: 1010.1111/j.14697610.2010.02271.x.

McEwen, B. S. (2012). Brain on stress: how the social environment gets under the skin. Proc Natl Acad Sci U S A., 109(Suppl 2), 17180-17185. doi: 17110.11073/pnas.1121254109. Epub 1121252012 Oct 1121254108 .

Monk, C., Spicer, J., \& Champagne, F. A. (2012). Linking prenatal maternal adversity to developmental outcomes in infants: the role of epigenetic pathways. Dev Psychopathol., 24(4), 1361-1376. doi: 1310.1017/S0954579412000764.

Oliver, B. R., Kretschmer, T., \& Maughan, B. (2014). Configurations of early risk and their association with academic, cognitive, emotional and behavioural outcomes in middle childhood. Soc Psychiatry Psychiatr Epidemiol., 49(5), 723-732. doi: 710.1007/s0012700013-00756-00121. Epub 02013 Aug 00123.
Patten, S. B., Beck, C. A., Kassam, A., Williams, J. V., Barbui, C., \& Metz, L. M. (2005). Long-term medical conditions and major depression: strength of association for specific conditions in the general population. Can $J$ Psychiatry., 50(4), 195-202.

Patten, S. B., Wilkes, T. C., Williams, J. V., Lavorato, D. H., ElGuebaly, N., Schopflocher, D., . . . Bulloch, A. G. (2014). Retrospective and prospectively assessed childhood adversity in association with major depression, alcohol consumption and painful conditions. Epidemiol Psychiatr Sci, 31, 18 .

Population Research Laboratory. (2013). Alberta Survey Methodology Report: Department of Sociology, University of Alberta.

Raphael, K. G., Chandler, H. K., \& Ciccone, D. S. (2004). Is childhood abuse a risk factor for chronic pain in adulthood? Curr Pain Headache Rep., 8(2), 99-110.

Reiser, S. J., McMillan, K. A., Wright, K. D., \& Asmundson, G. J. (2014). Adverse childhood experiences and health anxiety in adulthood. Child Abuse Negl., 38(3), 407-413. doi: 410.1016/j.chiabu.2013.1008.1007. Epub 2013 Sep 1016.

Shonkoff, J. P., Boyce, W. T., \& McEwen, B. S. (2009). Neuroscience, molecular biology, and the childhood roots of health disparities: building a new framework for health promotion and disease prevention. JAMA., 301(21), 22522259. doi: 2210.1001/jama.2009.2754. 
Slavich, G. M., \& Irwin, M. R. (2014). From stress to inflammation and major depressive disorder: a social signal transduction theory of depression. Psychol Bull., 140(3), 774-815. doi: 710.1037/a0035302. Epub 0032014 Jan 0035313.

Springer, K. W., Sheridan, J., Kuo, D., \& Carnes, M. (2007). Long-term physical and mental health consequences of childhood physical abuse: results from a large population-based sample of men and women. Child Abuse Negl., 31(5), 517530.

Statistics Canada. (2012) Census Profile (2011 Census). Ottawa, ON: Statistics Canada.

Williams, L. M. (1995). Recovered memories of abuse in women with documented child sexual victimization histories. J Trauma Stress., 8(4), 649-673.

Wolfe, D. A., Crooks, C. V., Lee, V., McIntyre-Smith, A., \& Jaffe, P. G. (2003). The effects of children's exposure to domestic violence: a meta-analysis and critique. Clin Child Fam Psychol Rev., 6(3), 171-187.

Wu, L. J., Toyoda, H., Zhao, M. G., Lee, Y. S., Tang, J., Ko, S. W., . . Zhuo, M. (2005). Upregulation of forebrain NMDA NR2B receptors contributes to behavioral sensitization after inflammation. J Neurosci., 25(48), 1110711116. 